\title{
Tres décadas de relaciones entre América Latina y España (1990-2020): Síntesis de las fortalezas y debilidades generadas. Propuestas de acción a futuro
}

\section{Three Decades of Relations between Latin America and Spain (1990-2020): Synthesis of the Strengths and Weaknesses Generated. Proposals for Future Action}

\author{
Iván González Sarro ${ }^{1}$ \\ ORCID: https://orcid.org/0000-0002-1296-4435 \\ Pedro Pérez Herrero ${ }^{2}$ \\ ORCID: https://orcid.org/0000-0003-0719-404X
}

\section{Instituto Universitario de Investigación en Estudios Latinoamericanos (IELAT) Universidad de Alcalá (UAH)}

\footnotetext{
${ }^{1}$ (ivan.gonzalezs@edu.uah.es) Doctor en Historia por la Universidad de Alcalá. Investigador y profesor colaborador del IELAT. Principales líneas de investigación: Desarrollo económico de América latina, economía política, geopolítica y humanidades digitales. Premio Extraordinario de Doctorado de las tesis leídas en el año académico 2017-2018 en la Rama de Artes y Humanidades en la Universidad de Alcalá (UAH). Sus últimas publicaciones: (2019): Políticas públicas neoliberales y desigualdad. México, Estados Unidos, Francia y España (1973-2013), Madrid: Marcial Pons. (2019): "Las reformas del mercado de trabajo en Estados Unidos (1973-2013) y sus impactos sobre la desigualdad de ingresos", Revista de Economía Laboral, Vol.15, Núm. 1, pp. 34-76; (2020): "Veinte años de relaciones estratégicas de la Unión Europea con América Latina y el Caribe (1999-2019): análisis de la evolución de sus 'tres pilares' fundamentales", Foro Internacional, Colegio de México, vol. LX-3, Núm. 241, julio-septiembre, pp. 1121-1167.

2 (pedro.perezherrero@uah.es) Doctor en Historia por El Colegio de México. Catedrático de historia, Universidad de Alcalá. Director del IELAT. Principales líneas de investigación: Historia política, económica y relaciones internacionales. Premio a la excelencia en la dirección de tesis doctorales (grado senior, rama humanidades, ciencias sociales y jurídicas), Universidad de Alcalá (3 de octubre de 2020). Sus últimas publicaciones: (2020): "Historia y prospectiva en tiempos de globalización", en Eduardo Cavieres y Pedro Pérez Herrero (Eds.), Historia y prospectiva, Madrid, Marcial Pons-IELAT, pp. 37-68. (2020): "Imaginando el futuro de la Asociación de América Latina y el Caribe con la Unión Europea", en Héctor Casanueva (Coord.), Unión Europea y América Latina. Una asociación estratégica para los desafios globales, Madrid, Marcial Pons, pp. 109-132. (2019): "Pasado y presente de la precarización y la informalidad en América Latina. Reflexiones desde la Historia", en Eduardo Cavieres Figueroa y Pedro Pérez Herrero (Coords.), Informalidad e Historia ¿Precarización u oportunidades?, Valparaíso, Ediciones Pontificia Universidad Católica de Valparaíso, Chile, 2019, pp. 37-58.
} 
Recibido: 20-01-2021

Aceptado: 29-06-2021

\title{
Resumen
}

En este texto se analizan las relaciones económicas y políticas que se dieron entre América Latina y España durante el período 1990-2020. Se pone de relieve que, desde la década de 1990, una vez que España se integró en la Comunidad Económica Europea (CEE) en 1986, las relaciones económicas y políticas entre España y América Latina se intensificaron y profundizaron, al mismo tiempo que las líneas de acción fueron cambiando en función de las improntas de los diferentes gobiernos españoles y los cambios en América Latina y en el escenario internacional. En el trabajo se hace un balance de síntesis de las fortalezas y debilidades generadas en dichas relaciones en el período investigado. La principal hipótesis interpretativa del trabajo es que, como sugiere dicho balance, algunos elementos de las relaciones pueden transformarse, profundizarse, reorientarse o sencillamente modificarse, sin despreciar, por supuesto, la base de todo lo construido y conseguido a lo largo de todos estos años de relaciones. Por ello, en las conclusiones se aportan algunas reflexiones relevantes a tener en cuenta para el diseño de las relaciones entre España y América Latina en las décadas venideras.

Palabras-clave: Relaciones América Latina-España, relaciones diplomáticas, cooperación, flujos económicos, inversión extranjera directa.

\begin{abstract}
This text analyzes the economic and political relations that existed between Latin America and Spain during the period 1990-2020. It is highlighted that, since the 1990s, once Spain joined the European Economic Community (EEC) in 1986, economic and political relations between Spain and Latin America intensified and deepened, at the same time as the lines of the actions were changing depending on the imprints of the different Spanish governments and the changes in Latin America and on the international scene. In the work, a synthesis balance is made of the strengths and weaknesses generated in these relationships in the investigated period. The main interpretive hypothesis of the work is that, as this balance suggests, some elements of relationships can be transformed, deepened, reoriented or simply modified, without neglecting, of course, the basis of everything built and achieved throughout all these years of relationships. Therefore, the conclusions provide some relevant reflections to
\end{abstract}


take into account for the design of relations between Spain and Latin America in the coming decades.

Keywords: Latin America-Spain relations, diplomatic relations, cooperation, economic flows, foreign direct investment.

\section{Introducción}

Este texto se centra en las relaciones entre América Latina y España. El análisis de estas relaciones se ha basado con frecuencia en su historia compartida durante varios siglos. Ello ha generado vínculos, interdependencias -de muy distinto alcance y naturaleza- y realidades comunes que parecen haber estado presentes en esa relación entre la región latinoamericana y España a lo largo del tiempo.

Por otro lado, la relación entre España y América Latina se ha pensado frecuentemente desde España en clave económica "utilitaria". Así, se reflexiona sobre cuál puede o debe ser el papel de la antigua metrópoli en el espacio que ocupan sus excolonias (Rodríguez, 2018: 215-216). Desde esta posición, se califica a esta relación como "excepcional", defendiendo una posición de España como puente "natural" y directo entre Europa y América Latina. Se plantea la existencia de una "obligación moral" española de participar como mediadora en los procesos de paz, "en virtud de las responsabilidades derivadas de los estrechos vínculos históricos". "En definitiva, se plantea el valor de España en la geopolítica mundial en relación con el estado de sus lazos con América Latina" (Jorge, 2018: 21-23).

Independientemente de estas cuestiones, sin duda controvertidas, algunas todavía no resueltas, lo cierto es que la historia compartida desde la colonización del Nuevo Mundo a finales del siglo XV ha transmitido cierta homogeneidad de valores sociales, creencias religiosas, cultura y una misma lengua. Todos estos factores predeterminaron un carácter especial de interacción y profundidad en las relaciones de España con América Latina y en la política de esta región con España. En consecuencia, sin la consideración de estos factores fundamentales no es posible comprender este carácter especial y singular, ni los valores e intereses que se presentan en estas relaciones.

A ello hay que unir además el carácter multidimensional de las mismas, abarcando ámbitos diversos-que desbordan las relaciones político-diplomáticas y las relaciones puramente económicas- incluyendo una amplia gama de vínculos de la más diversa naturaleza y alcance: social, cultural, científicotécnico, programas de cooperación al desarrollo, instalación de empresas españolas en la región latinoamericana, desarrollo de flujos migratorios, etc. 
Tras el final de la dictadura franquista y el retorno de la democracia en España, que hizo posible su homologación internacional, este conjunto de relaciones con los países latinoamericanos se intensificaron. Apunta Delgado que "primero se normalizaron las relaciones diplomáticas con aquellos que no se resignaron a ese paso mientras perviviese el franquismo, entre ellos México. No obstante, no sería hasta después de la integración de España en la Comunidad Económica Europea (CEE) en 1986, que las relaciones de España con América Latina marcarían una nueva dinámica” (Delgado, 2003: 150-151).

En vísperas del Quinto Centenario del Descubrimiento de América, en 1992, creció la intensidad de los contactos político-diplomáticos de España con Latinoamérica. España se presentó como "hermano europeo moderno" en la consolidada familia iberoamericana (Pérez Herrero, 2003: 327). Surgió "la mutua necesidad de superar una especie de gravitación geográfica de los países ibéricos y latinoamericanos, o sea, vencer la limitación de sus esfuerzos integracionistas por regiones propias". Se puso a la orden del día la meta de alcanzar una positiva interdependencia mediante una "especie del puente trasatlántico, una estructura permanente de interacción eficaz de los Estados", que permitiera encontrar conjuntamente soluciones estratégicas concretas (Yákovlev, 2013: 94).

Ello se materializó "en la celebración en 1991 de la I Cumbre Iberoamericana de Jefes de Estado y de Gobierno, que tuvo lugar en Guadalajara, México. En 1992 la anfitriona de la siguiente cumbre fue la capital española, haciéndose coincidir sus sesiones con la conmemoración del Quinto Centenario del Descubrimiento de América y la Exposición Universal de Sevilla. En 1993 los mandatarios iberoamericanos se reunieron en Salvador de Bahía (Brasil), en 1994 lo hicieron en Cartagena de Indias (Colombia), y así continuarían en lo sucesivo esos encuentros al más alto nivel hasta llegar a nuestros días. Con la perspectiva de casi dos siglos desde el comienzo del proceso independentista, las relaciones con América Latina adquirían por primera vez ese rango gubernamental, configurando un foro de debate de políticas y proyectos comunes" (Delgado, 2003: 153).

Como se ha dicho, el propósito de este artículo es el análisis de estos múltiples vínculos que tejen las relaciones entre América Latina y España a lo largo de las tres décadas que van desde la celebración de esta primera Cumbre Iberoamericana hasta el momento actual. En esencia, se pretende hacer un análisis de síntesis de las fortalezas y debilidades que han generado estas relaciones -básicamente en las esferas política y económica- en este periodo, tratando de contrastar la hipótesis central del trabajo en el sentido de que algunos elementos de las relaciones entre España y América Latina pueden transformarse, profundizarse, reorientarse o sencillamente modificarse, sin despreciar, por supuesto, la base de todo lo construido y conseguido a lo largo 
de todos estos años de relaciones. Por otro lado, se presenta una propuesta de acción a futuro que contempla distintas acciones. Debe tenerse en cuenta, por otra parte, que tanto América Latina como España se encuentran ante un mundo que ha cambiado radicalmente como consecuencia de la pandemia de la COVID-19 (Haider y Clemente, 2020: V), y que dibuja un escenario marcado por la incertidumbre, lo que, posiblemente pueda incidir en estas relaciones. La coyuntura en que nos ha sumido la pandemia y los esfuerzos para la posterior reconstrucción quizá pueda suponer un estímulo relevante para repensar la política de España hacia América Latina. Tal vez sea una ventana de oportunidad única y, según nuestra opinión, España debería dar claras muestras de que América Latina le importa, adoptando políticas en esa dirección.

El trabajo se organiza del siguiente modo. En el siguiente apartado, el segundo, se desarrolla el marco teórico del trabajo, comentándose someramente las facetas o dimensiones de las relaciones entre América Latina y España y las variables de estudio. El apartado tercero se dedica a hacer un balance de las fortalezas y debilidades que se han ido generando a lo largo del tiempo en estas relaciones, principalmente en los ámbitos político y económico. Finalmente, en las conclusiones, con un tono propositivo, se realizan algunas reflexiones sobre las posibles propuestas de acción a futuro en relación con cada una de las variables de estudio.

\section{Marco teórico: dimensiones de las relaciones entre América Latina y España. Variables de estudio}

Como se ha comentado, tras el cambio político que experimentó España después de la muerte del dictador Franco, se produjo una notable renovación y ampliación del papel que tradicionalmente había tenido América Latina en la vida española. De esta forma, la política iberoamericana registró un profundo cambio con relación a la política del franquismo. Este cambio se iba a producir gradualmente, culminando realmente en 1992, como hemos visto. Los principales ejes sobre los que se iba a desarrollar esta nueva política iberoamericana, basada en la intensificación de las relaciones con América Latina en todos los ámbitos, serán cinco, todos ellos directamente relacionados: (a) el apoyo a la democracia y la defensa de los derechos humanos; (b) la elevación del perfil político y de la concertación en las relaciones bilaterales; (c) el desarrollo de una política de cooperación al desarrollo; (d) la puesta en marcha y consolidación de las Cumbres Iberoamericanas, y (e) la intensificación de las relaciones entre la UE y América Latina. (Del Arenal, 2011a: 119-122).

Estos diferentes ámbitos podrían agruparse en tres dimensiones básicas: política, económica y social y cultural. 
A nivel politico, cabe destacar las Cumbres iberoamericanas así como las Cumbres entre los países de la Unión Europea y de América Latina y el Caribe, inauguradas en Río de Janeiro, a finales de julio de 1999; las visitas recurrentes de jefes de Estado y otros altos funcionarios latinoamericanos a Madrid y del gobierno español o de la Corona a las distintas capitales latinoamericanas; los diferentes apoyos que los gobiernos españoles han prestado a los procesos de paz en América Latina, desde Contadora hasta Colombia; la reiterada defensa de los problemas latinoamericanos en las distintas instancias de la Unión Europea y la presencia de los temas latinoamericanos en las cumbres hispanonorteamericanas (Fazio, 2000: 41).

Los vínculos económicos, relacionados fundamentalmente con el comercio y la inversión, por una parte, y la cooperación, por otra, han articulado la relación entre España y América Latina de una manera destacada. Sin duda, el componente económico en las relaciones entre España y América Latina ha sido muy intenso. España se ha convertido en uno de los principales inversores en América Latina; la mayor parte de su cooperación internacional se destina a los países de la región; y es muy significativo el tráfico comercial entre España y América Latina. A nivel económico, América Latina ha servido como espacio de aprendizaje para la internacionalización de las empresas españolas y se ha convertido en una zona a través de la cual fortalece y multilateraliza su inserción internacional (Fazio, 2000: 42). Durante la década de 1990, América Latina se convirtió en el objetivo principal de muchas empresas españolas en su proceso de internacionalización. Para ello se beneficiaron de las transformaciones económicas y estructurales que tuvieron lugar en la región latinoamericana y de la privatización de empresas del sector público, una vez superada la "década perdida". Las empresas españolas siguen aportando mucho a las economías latinoamericanas donde están implantadas, pese a que en el terreno empresarial también se observa un fenómeno similar a lo que ocurre con la presencia española en el mundo, consistente, en términos generales, en una menor atención hacia América Latina (Malamud et al., 2020: 59). En los últimos años, especialmente desde 2008, la mayoría de las grandes empresas españolas han diversificado su implantación geográfica, debido básicamente al impacto de la crisis financiera global así como a las dificultades y turbulencias en América Latina. De este modo, si bien se ha reducido la importancia relativa de la región en la generación de beneficios para las casas matrices, ha aumentado la de algunos países en particular. En líneas generales ha disminuido la atención hacia algunos países que presentan unos entornos cada vez más complicados y ha mejorado en otros (Malamud et al., 2020: 79-80). Por otro lado, la inversión directa de origen latinoamericano en España se ha consolidado en los últimos años como fenómeno económico y empresarial. La llegada de capitales de ese origen no debe ser infravalorada, debiendo hablarse de la bidireccionalidad de 
los flujos de inversión. Partiendo de niveles casi inexistentes a principios de siglo, actualmente las empresas de origen latinoamericano se han integrado en el tejido empresarial español. Entre algunas de las características destacables de este flujo está la fuerte presencia de capital mexicano, incluyendo fondos tecnológicos de venture capital, que ya están realizando operaciones de adquisición de empresas españolas, el peso no menor de emprendedores argentinos, especialmente en tech, o la mayor participación de ciertas empresas multilatinas en el régimen español de holding (Entidades de Tenencia De Valores Extranjeros-ETVE) (Malamud et al., 2020: 81).

La dimensión social y cultural también ha cimentado los vínculos entre España y América Latina. Ello se ha plasmado, entre otros, en el fenómeno migratorio, es decir la presencia de importantes comunidades de españoles en América Latina y de nutridas colonias de latinoamericanos en España. El incremento y el peso de la inmigración latinoamericana en España tiene relación con los lazos históricos y sociales que fue forjando la emigración española a lo largo del pasado siglo, tanto la de índole económica como la política, sin remontarnos a etapas anteriores. Pero también con decisiones políticas que van desde la firma de convenios bilaterales para regular los flujos migratorios con diversos países latinoamericanos, como Colombia, Ecuador, República Dominicana; a las favorables condiciones para la obtención de la nacionalidad española para hijos y nietos de españoles; a las mayores facilidades para la obtención y renovación del permiso de residencia y el acceso a la nacionalidad tras solo dos años de residencia legal, sin olvidar los convenios de doble nacionalidad firmados desde 1958 con la mayor parte de los países latinoamericanos. (García et al., 2009: 56). También deben contemplarse en esta dimensión los lazos culturales, académicos y de investigación. Dentro de ellos, se han desarrollado programas bilaterales y regionales de promoción de la lengua y la cultura en español, iniciada por el Instituto Cervantes con varias instituciones de la región latinoamericana. Igualmente, se ha avanzado en la creación de un espacio iberoamericano de movilidad de estudiantes y profesionales dirigido a reequilibrar aquellos países con déficit de profesionales en determinados sectores e incrementando los niveles de excelencia en todos los Estados partícipes. En España se ha seguido recibiendo con interés las manifestaciones culturales latinoamericanas impulsadas por colectivos de América Latina. La Casa de América ha desplegando un intenso programa de actividades de toda índole y sigue siendo el gran foro de debate, reflexión y encuentro de la cultura latinoamericana en Madrid.

Dentro de este marco general, puede decirse que cinco variables han estado muy presentes en los análisis que se han realizado sobre las relaciones entre América Latina y España: 
a) Existencia de una comunidad cultural iberoamericana

Como se ha dicho al comienzo, el análisis de estas relaciones se ha basado con frecuencia en su "historia compartida" durante varios siglos. Hasta tal punto es así que se llega a plantear, desde la perspectiva española, que estos vínculos seculares establecidos a ambos lados del Atlántico tienen una particular "dimensión identitaria", basada en la "idea de la existencia de una comunidad de cultura, lengua y valores entre España y las repúblicas americanas" (Del Arenal, 2011a: 2-3), y en la "convicción de que la región latinoamericana constituía una prolongación en el mundo de la identidad nacional española" (Delgado, 2003: 124).

No obstante, tal como afirma Rodríguez, esta "idea de la existencia de una comunidad de intereses afines entre los países latinoamericanos con su antigua metrópoli ha sido cuestionada y contestada desde diferentes lugares" (2018: 216) y se "vive de forma contradictoria en América Latina" como consecuencia de la dimensión identitaria indígena afirmada por ciertos países de la región latinoamericana. No se puede olvidar, en este sentido, que, como explica Del Arenal, "esos países se independizaron, hace doscientos años, precisamente de España, y que la afirmación de su propia identidad nacional se realizó en casi todos los casos frente a España y lo español, pero sin poder obviar sus profundas raíces hispánicas que continúan presentes en el momento actual" (Del Arenal, 2011a: 3).

Ciertamente, ha sido habitual subrayar que ha habido una "historia compartida" entre España y el conjunto de los países que componen América Latina. Se ha repetido hasta la saciedad que, desde la incorporación de las tierras americanas al sistema imperial hispánico en el siglo XVI, se fueron creando en los distintos virreinatos, audiencias, capitanías y gobernaciones sociedades con valores socioculturales hispanos (familia, religión, lengua, principios jurídicos); y se ha explicado que cuando se crearon las repúblicas independientes a comienzos del siglo XIX no se cortó con este legado. En consecuencia, se ha interpretado que existe al día de la fecha una comunidad cultural iberoamericana que debe ser aprovechada para actuar como fermento de una integración supranacional.

b) Efectos positivos de las inversiones realizadas por las empresas y los bancos españoles en América Latina junto con la cooperación ofrecida por los gobiernos españoles en el desarrollo económico y social de los países de América Latina

Efectivamente, en muchos de estos análisis se resalta el papel desempeñado por la inversión de empresas españolas en América Latina, que ha tenido un impacto muy significativo en la modernización y crecimiento de las economías de los países latinoamericanos durante los últimos veinticinco o treinta años. 
c) Política española hacia América Latina como política de apoyo

Este aspecto es destacado en muchos análisis. Cómo en España, los distintos gobiernos desde la transición a la democracia y tras su incorporación a la Unión Europea en 1986 se han distinguido por haber construido una política latinoamericana en su acción exterior, que se ha expresado en un espacio de intermediación entre la dimensión bilateral y multilateral en su proyección internacional. España era, junto con EEUU, uno de los pocos países del mundo con una política de conjunto coherente para la región (Malamud et al., 2020: 31).

No obstante, podría decirse que la política exterior española hacia América Latina ha sido tradicionalmente una política exterior no incluyente, en el sentido de que no siempre se han tenido en cuenta los intereses de los países y de las sociedades civiles latinoamericanas. Todo ello ha generado un discurso retórico, a veces falto de sentido práctico, y que ha propiciado una cierta incomprensión

d) Relevancia de las relaciones de España y la Unión Europea con América Latina

Se ha resaltado en muchos análisis la importancia de las relaciones de España y la Unión Europea con América Latina, destacando a la UE como el mayor donante multilateral de AOD en ALC y el primer donante si se considera en su conjunto los fondos aportados por los Estados miembros y la Comisión Europea. La UE dispone de la mayor red mundial de acuerdos comerciales con ALC.

e) Falta de estrategias de cooperación a largo plazo.

Esta variable tiene un carácter propositivo y prospectivo. Se trata de subrayar cómo se entiende que se tiene que tener una visión a largo plazo, planteándose la posibilidad de contemplar un espacio más amplio en estas relaciones entre América Latina y España, que abarcara a más países de la vertiente atlántica, generándose un espacio atlántico de acción común.

En el siguiente apartado se analizan con cierto detalle las facetas concretas de las relaciones entre España y América Latina asociadas a la actividad política y económica. Este análisis nos permitirá hacer un balance de las mismas y realizar una propuesta de acciones futuras en relación con cada una de estas cinco variables señaladas, que se recogen en el apartado de Conclusiones. 


\section{Balance de las fortalezas y debilidades generadas en las relaciones entre América Latina y España en los planos político y económico}

\subsection{Relaciones político-diplomáticas}

En el plano político, siguiendo al profesor Del Arenal, uno de los más destacados estudiosos de las relaciones diplomáticas de España con América Latina, a la hora de analizar estas relaciones deben tenerse en cuenta los condicionantes que han reducido los márgenes relativos de autonomía de la política española hacia Latinoamérica. El primer condicionante ha sido la política de Estados Unidos hacia la región latinoamericana. Como bien explica Celestino del Arenal, "desde el siglo XIX hasta nuestros días, y muy especialmente a partir del momento en que se institucionaliza la condición de aliados entre EEUU y España, Estados Unidos, que tiene intereses estratégicos, políticos y económicos directos en la zona, ha sido un condicionante muy importante, especialmente cuando España ha tratado de desarrollar una política activa y autónoma en la región, como sucedió en el plano estratégico-político en los años ochenta respecto de Centroamérica con los gobiernos socialistas de Felipe González (1982-1996) o, con los gobiernos socialistas de Rodríguez Zapatero (2004-2011) respecto a las relaciones con algunos gobiernos iberoamericanos, especialmente en el caso de Cuba" (Del Arenal, 2011a: 127). El segundo factor condicionante deriva de la pertenencia de España a la UE. Los efectos derivados de esa pertenencia a la UE son dobles. Por un lado, España ya no solo tiene una política latinoamericana propia, sino que además tiene las políticas de la UE hacia América Latina y se ve condicionada de manera mucho más directa por las políticas latinoamericanas del resto de los países miembros. Ello va a reducir de forma importante la autonomía y los objetivos políticos y económicos de la política hacia América Latina, limitada por la condición de Estado miembro. De estos dos condicionantes se van a derivar contradicciones. Por un lado, la contradicción entre iberoamericanidad y atlantismo y, por el otro, entre iberoamericanidad y europeísmo, que van a reducir considerablemente la autonomía de España hacia América Latina y que va a provocar tensiones bilaterales. Por ello, España, ya desde su incorporación a las Comunidades Europeas, puso en marcha una "estrategia triangular", cuyos vértices serían España, la UE y América Latina. Tal como destaca Del Arenal, es "desde esta perspectiva triangular desde la que hay que entender la pretensión manifestada reiteradamente, con mayor o menor intensidad, por todos los gobiernos democráticos españoles de actuar como "puente" en las relaciones entre Europa y América Latina" (Del Arenal, 2011b: 78-79).

Por otro lado, conviene tener presente que las relaciones políticodiplomáticas de España con América Latina se han desarrollado a cuatro 
niveles. En primer lugar, tal como señala Del Arenal, "el bilateral, que se concreta en la política que España desarrolla de forma individual con cada uno de los países latinoamericanos, sobre la base del principio de indiscriminación" (2011a: 130). Señala Fazio que, "la dimensión bilateral adoptó como componentes básicos la suscripción de tratados de amistad y cooperación en los que se contemplaban programas de fomento a las relaciones comerciales y de inversiones, el estímulo a la presencia de empresas españolas en el continente y la cooperación al desarrollo. Estos acuerdos surgían de la necesidad de las autoridades españolas de promover nuevos y variados vínculos económicos en la industria, los servicios, la inversión y la cooperación al desarrollo, lo que implicaba movilizar la inversión del sector privado y de los fondos públicos. Por otro lado, la estrategia bilateral se focalizó en el apoyo a la democracia y a los derechos humanos, razón por la cual muchos de estos tratados incluyeron una cláusula democrática que evidenciaba la validez de los mismos si en el poder se encontraban fuerzas democráticas" (Fazio, 2000: 63). "Este ámbito bilateral está cobrando cada vez más importancia, como consecuencia de la creciente heterogeneidad y división política de los países latinoamericanos y de la cada vez más imperiosa necesidad que tiene España de desarrollar políticas bilaterales adaptadas a cada país" (Del Arenal, 2011a: 131).

El segundo ámbito es el subregional, "que hace referencia a las políticas específicas que se articulan, en ocasiones, respecto de ciertas subregiones de América Latina, caso, por ejemplo, de la política centroamericana que los gobiernos socialistas de Felipe González desarrollaron con éxito especialmente en la década de los años ochenta del siglo XX. Este ámbito, como es lógico, es el que está más sujeto a las coyunturas específicas" [...] Las políticas subregionales, "mucho más complejas y difíciles de articular y dependientes de situaciones muy particulares, son las que han permitido en una medida significativa reforzar la imagen y la política de España en América Latina" (Del Arenal, 2011a: 131).

En tercer lugar, está el nivel regional, "que se plasma en la política que España articula respecto del conjunto de América Latina, es decir, respecto de los 21 Estados iberoamericanos, a través, especialmente, pero no de forma exclusiva, de las Cumbres Iberoamericanas, puestas en marcha a partir de 1991", como ya se ha comentado, "y que tiene como objetivo final la afirmación de la Comunidad Iberoamericana, tanto hacia el interior de la misma, como en su proyección internacional. Esta política regional, que España viene desarrollando tradicionalmente, ha condicionado en algunos casos de manera significativa las políticas desarrolladas en los demás ámbitos, especialmente en el bilateral" (Del Arenal, 2011a: 131).

Finalmente, se encuentra el ámbito europeo. Ya se ha señalado que a partir del ingreso de España en la UE España no solo tiene una política propia, sino que 
además debe cumplir con los compromisos de la UE hacia América Latina. Este nivel europeo, "ha cobrado creciente importancia, dada la incidencia que el mismo tiene en todos los demás, produciéndose una europeización de la política iberoamericana. Se trata de un ámbito que, en principio, refuerza todos los anteriores, aunque también, como se ha visto, los condiciona fuertemente, provocando contradicciones en las relaciones de España con América Latina” (Del Arenal, 2011a: 131-132).

Además de los anteriores, encontramos un quinto nivel, "de naturaleza no estrictamente gubernamental, de creciente importancia, que hace referencia a la actividad exterior desarrollada por toda una serie de actores españoles de muy variada naturaleza y alcance, públicos y privados, que van desde las Comunidades Autónomas y las Corporaciones Locales, con importantes proyecciones en América Latina en algunos casos, especialmente en términos de programas de cooperación al desarrollo, hasta las empresas, organizaciones no gubernamentales, universidades, fundaciones y asociaciones de todo tipo, que tienen una cada vez más creciente e importante proyección en América Latina" (Del Arenal, 2011a: 132).

Por otra parte, "España ha promovido la integración y el multilateralismo como mejor respuesta a la realidad internacional. Por ello ha apoyado los diferentes procesos de integración económica, política y comercial como la Unión de Naciones de América del Sur (UNASUR), el Sistema de la Integración Centroamericana (SICA) o el MERCOSUR", según se sostiene por parte del Ministerio de Asuntos Exteriores, Unión Europea y Cooperación ${ }^{3}$.

No obstante, ante la creciente fragmentación y heterogeneidad de América Latina, la política exterior española debe poner un mayor énfasis en lo bilateral, sin abandonar un enfoque regional, según nuestro punto de vista. El reforzamiento de las relaciones bilaterales puede consolidar los lazos con aquellos países más próximos o más afines y con aquellos con los que existen mayores intereses comunes, como son, por ejemplo, México, Brasil, Argentina, Chile, Colombia y Perú.

Cabe apuntar, finalmente, que desde la perspectiva latinoamericana se ha observado "una diferencia marcada en las formas de relación de España con los países más grandes y los más pequeños de América Latina. Mientras que, con relación a los segundos, en algunas ocasiones Madrid ha intentado recurrir a diferentes mecanismos de presión para hacer valer sus principios de Estado y ha tratado de ser más incisivo a la hora de delimitar un marco general de relación [...], con respecto a los más grandes su política ha sido más convencional, de tolerancia y menos impulsiva, en razón del peso de estos países en el concierto continental y debido a los grandes intereses económicos que a veces han estado en juego" (Fazio, 2000: 52).

3 Visto en: http://www.exteriores.gob.es/Portal/es/PoliticaExteriorCooperacion/Iberoamerica/ Paginas/-EspEnIberoamerica.aspx, consultado el 22 de diciembre de 2020.

Araucaria. Revista Iberoamericana de Filosofía, Política, Humanidades y Relaciones Internacionales, año $23, \mathrm{n}^{\circ} 47$. Segundo cuatrimestre de 2021. Pp. 529-560. ISSN 1575-6823 e-ISSN 2340-2199 https://dx.doi.org/10.12795/araucaria.2021.i47.23 


\subsection{Cooperación}

Tradicionalmente, la cooperación, especialmente en su vertiente de Ayuda Oficial al Desarrollo (AOD), ha sido uno de los elementos centrales de la política de España hacia América Latina, y uno de los ejes con el que los gobiernos democráticos españoles han querido subrayar el sentido de la nueva política hacia Latinoamérica. América Latina y el Caribe (ALC) "han sido una prioridad de la política de cooperación de España desde el inicio de la cooperación moderna a mediados de los años ochenta" (Freres, 2011: 57).

Los datos y la información disponible sustentan esta afirmación y reflejan el compromiso de España con el desarrollo de la región ALC. Así, según datos de la Organización para la Cooperación y el Desarrollo Económico (OCDE), referidos a 2017 (última información oficial hecha pública), España es el primer donante bilateral del Comité de Ayuda al Desarrollo (DAC) (Development Assistance Committee -DAC), en términos relativos, de acuerdo con el porcentaje que destina a ALC sobre el total de su AOD. En efecto, entre $2010 \mathrm{y}$ 2017, España destinó a ALC un 56\% de su AOD total en ese período (Tabla I).

Tabla I. Ayuda a América Latina y el Caribe por donante del

Comité de Asistencia para el Desarrollo (Development Assistance Committee-DAC) de la OCDE, 1970-2017

(En millones de dólares USA 2016 y \% sobre el total)

\begin{tabular}{lrrrrrrc}
\hline \multicolumn{1}{c}{ Donante } & $1970-$ & $1980-$ & $1990-$ & $2000-$ & $2010-$ & $\begin{array}{c}2010-2017 \\
\% \text { de cada } \\
\text { donante } \\
\text { del DAC }\end{array}$ & $\begin{array}{c}2010-2017 \\
\text { ALC como } \% \\
\text { de la AOD de } \\
\text { cada donante }\end{array}$ \\
\hline Australia & 1979 & 3989 & 1999 & 2009 & 21 & $0 \%$ & $1 \%$ \\
Austria & 9 & 19 & 33 & 35 & 26 & $0 \%$ & $7 \%$ \\
Bélgica & 34 & 45 & 82 & 84 & 80 & 15 & $10 \%$ \\
Canadá & 134 & 240 & 233 & 316 & 454 & $7 \%$ & $18 \%$ \\
Rep. Checa & - & - & 0 & 9 & 1 & $0 \%$ & $3 \%$ \\
Dinamarca & 12 & 15 & 76 & 101 & 48 & $1 \%$ & $5 \%$ \\
Finlandia & 7 & 18 & 27 & 34 & 38 & $1 \%$ & $8 \%$ \\
Francia & 114 & 293 & 289 & 242 & 862 & $14 \%$ & $17 \%$ \\
Alemania & 444 & 652 & 642 & 560 & 1.124 & $18 \%$ & $14 \%$ \\
Grecia & - & - & 0 & 2 & 1 & $0 \%$ & $2 \%$ \\
Hungría & 13 & 36 & 0 & 0 & 0 & $0 \%$ & $2 \%$ \\
Islandia & - & - & - & 1 & 1 & $0 \%$ & $3 \%$ \\
Irlanda & 0 & 0 & 3 & 15 & 12 & $0 \%$ & $3 \%$ \\
Italia & 1 & 236 & 287 & 59 & 52 & $1 \%$ & $9 \%$ \\
Japón & 137 & 468 & 753 & 432 & -59 & $0 \%$ & $0 \%$ \\
& & & & & & & \\
\end{tabular}




\begin{tabular}{|c|c|c|c|c|c|c|c|}
\hline Corea & - & 0 & 6 & 33 & 104 & $2 \%$ & $9 \%$ \\
\hline Luxemburgo & - & - & 14 & 31 & 26 & $0 \%$ & $13 \%$ \\
\hline Países Bajos & 408 & 495 & 521 & 255 & 74 & $1 \%$ & $6 \%$ \\
\hline $\begin{array}{l}\text { Nueva } \\
\text { Zelanda }\end{array}$ & 2 & 1 & 2 & 5 & 4 & $0 \%$ & $1 \%$ \\
\hline Noruega & 8 & 44 & 112 & 122 & 249 & $4 \%$ & $16 \%$ \\
\hline Polonia & 4 & 7 & 0 & 3 & 0 & $0 \%$ & $0 \%$ \\
\hline Portugal & - & - & 1 & 3 & 7 & $0 \%$ & $3 \%$ \\
\hline R. Eslovaca & - & - & - & 0 & 0 & $0 \%$ & $2 \%$ \\
\hline Eslovenia & - & - & - & 0 & 0 & $0 \%$ & $1 \%$ \\
\hline España & - & 46 & 486 & 857 & 600 & $9 \%$ & $56 \%$ \\
\hline Suecia & 27 & 86 & 161 & 189 & 118 & $2 \%$ & $7 \%$ \\
\hline Suiza & 35 & 97 & 130 & 136 & 190 & $3 \%$ & $14 \%$ \\
\hline Reino Unido & 284 & 152 & 199 & 97 & 227 & $4 \%$ & $4 \%$ \\
\hline $\begin{array}{l}\text { Estados } \\
\text { Unidos }\end{array}$ & 1.267 & 1.989 & 1.780 & 2.014 & 2.085 & $33 \%$ & $10 \%$ \\
\hline $\begin{array}{l}\text { Total países } \\
\text { del DAC }\end{array}$ & 2.942 & 4.943 & 5.837 & 5.637 & 6.347 & $100 \%$ & $10 \%$ \\
\hline $\begin{array}{l}\text { Institucio- } \\
\text { nes UE }\end{array}$ & 89 & 240 & 642 & 773 & 972 & --- & $7 \%$ \\
\hline
\end{tabular}

Fuente: «Development Aid at a Glance. Statistics by Region. 3. America», 2019 edition, OCDE, París, p. 5.

Este porcentaje está muy encima de los porcentajes del resto de países que integran el DAC, poniendo de relieve la concentración de la cooperación española en ALC. Por otro lado, en el año 2008, según datos de la OCDE, España fue el primer donante bilateral, aportando a ALC casi 2.000 millones de dólares en AOD en ese año (Tabla II). 
Tabla II. Diez donantes principales para América Latina y el Caribe por importe, 2008

(En millones de dólares y \% sobre el total)

\begin{tabular}{|c|c|c|c|}
\hline Ranking & Donante & $\begin{array}{l}\text { AOD (Im- } \\
\text { porte) }\end{array}$ & $\begin{array}{l}\% \text { Total reci- } \\
\text { bido por ALC }\end{array}$ \\
\hline 1 & España & 1.976 & $21 \%$ \\
\hline 2 & Estados Unidos & 1.871 & $20 \%$ \\
\hline 3 & Instituciones UE & 1.108 & $12 \%$ \\
\hline 4 & Alemania & 818 & $9 \%$ \\
\hline 5 & Canadá & 482 & $5 \%$ \\
\hline 6 & $\begin{array}{l}\text { Banco Interamericano de } \\
\text { Desarrollo }\end{array}$ & 310 & $3 \%$ \\
\hline 7 & Japón & 269 & $3 \%$ \\
\hline 8 & Países Bajos & 230 & $2 \%$ \\
\hline 9 & Francia & 213 & $2 \%$ \\
\hline \multirow[t]{3}{*}{10} & Suecia & 200 & $2 \%$ \\
\hline & Otros donantes & 1.783 & $19 \%$ \\
\hline & Total & 9.262 & $100 \%$ \\
\hline
\end{tabular}

Fuente: «Development Aid at a Glance. Statistics by Region. 3. America», 2010 edition, OCDE, París, p. 2.

El peso relativo de España en cooperación "también es reflejo del menor interés que tienen otros países para ayudar al desarrollo latinoamericano" (Freres, 2011: 58).

Como se ha comentado, los intereses de acción exterior que han sustentado esta política por parte de España han sido variados. "Primero, la idea de que la cooperación es un instrumento de influencia de España en América Latina. Un segundo motivo es que se siente una responsabilidad histórica hacia los países de esta zona. En tercer lugar, se ha entendido que es una buena forma de complementar intereses «duros» como los comerciales o de seguridad (p. e., drogas, terrorismo, etcétera)" (Freres, 2011: 58).

En cuanto a las prioridades sectoriales, en el año 2008 se enfatizó por parte de España en los sectores sociales, particularmente en la gobernabilidad, así como en el desarrollo económico de los países latinoamericanos (Tabla III). 
Tabla III. Distribución sectorial de la Cooperación Española para América Latina y el

Caribe, 2008 y 2017

\begin{tabular}{lcccc}
\hline \multirow{2}{*}{ Sectores } & \multicolumn{2}{c}{ Año 2008} & \multicolumn{2}{c}{ Año 2017 } \\
\cline { 2 - 5 } & España & $\begin{array}{c}\text { Media } \\
\text { DAC }\end{array}$ & España & Media DAC \\
\hline Sectores sociales & 65,5 & 57,1 & 37,1 & 43,0 \\
$\quad$ Educación & 11,9 & 9,6 & 6,3 & 8,7 \\
$\quad$ Gobernabilidad y & 10,7 & 15,5 & 21,5 & 19,3 \\
$\quad$ sociedad civil & & & & \\
$\quad$ Agua y Saneamiento & 28,0 & 10,2 & 2,7 & 7,8 \\
$\quad$ Sectores Socia- & 6,7 & 4,2 & 3,5 & 5,3 \\
$\quad$ les Básicos* & & & & \\
$\quad$ Otras infraestructuras & - & - & 3,3 & 1,9 \\
$\quad$ sociales & & & & \\
Desarrollo económico & 4,0 & 10,3 & 9,8 & 21,4 \\
Sectores productivos & 6,2 & 9,0 & 14,2 & 6,8 \\
Multi-sectorial & 6,2 & 9,0 & 6,0 & 16,0 \\
Deuda & 10,3 & 3,4 & 0 & 2,6 \\
Apoyo programático & 1,8 & 3,0 & 3,4 & 5,5 \\
general & & & & \\
Otros & 6,0 & 8,1 & 29,5 & 4,6 \\
Total & 100,0 & 100,0 & 100,0 & 100,0 \\
\hline
\end{tabular}

Fuente: Elaboración propia con base en datos de la OCDE y «Development Aid at a Glance. Statistics by Region. 3. America», 2019 edition, OCDE, París, p. 11.

* Incluye salud y educación básica

Concuerda este planteamiento con lo que la Agencia Española de Cooperación Internacional para el Desarrollo (AECID) denominó «enfoque Objetivos de Desarrollo del Milenio/ODM+», "consistente en una orientación hacia tres ejes fundamentales: gobernabilidad democrática, cohesión social y desarrollo económico, con mayor peso en los dos primeros ejes" (Freres, 2011: $60)$.

Podría decirse, a tenor de los datos, que hasta la crisis de 2008, los rasgos que caracterizaban a la cooperación española eran su concentración en 
América Latina y el Caribe así como su carácter bilateral en gran medida y su diversificación en múltiples sectores.

Ahora bien, tal como apuntan Olivié y Pérez, "la crisis financiera y económica de finales de los 2000 forzó un cambio de ciclo económico y fiscal en España, que se tradujo en un recorte de la ayuda al desarrollo [...]. Dicho recorte no se repartió de forma homogénea entre todos los actores e instrumentos de la ayuda. La AOD canalizada a través de la UE no se vio alterada debido al sistema que determina la contribución de cada Estado miembro a la misma. Los recortes aplicados desde 2009 necesariamente alteraron los patrones de distribución geográfica y sectorial de la ayuda española" (2019). De acuerdo con los datos aportados por estos autores, a partir de la crisis financiera de 2008, "podría entenderse que el 43\% de la cooperación española del período 20132017se mantiene en el marco de los compromisos financieros obligatorios del país con la UE" (Olivié y Pérez, 2019).

De este modo, España se percibe como un donante volcado en América Latina y el Caribe, tal como se ha dicho. Los datos suministrados por la OCDE así lo evidenciarían: por encima del $37 \%$ de la ayuda se dirigió a esta región en el periodo 2013-2017, llegando al 20\% en los países de África Subsahariana (Gráfico 1)

Gráfico 1. Reparto geográfico de la ayuda española (AOD neta total en millones de dólares corrientes, acumulado 2013-2017, repartido en \%)

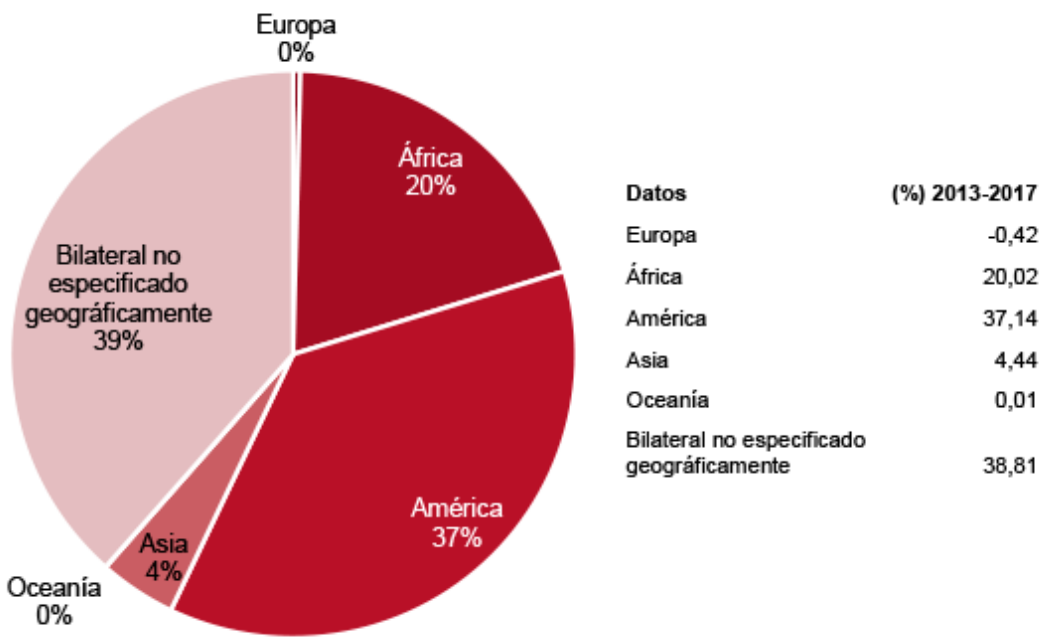

Fuente: Olivié y Pérez, 2019, basados en OCDE, OECD.Stat. 
No obstante, debe tenerse en cuenta que "los datos mostrados por la OCDE suelen identificar a las instituciones europeas como un espacio multilateral más a través del cual los donantes UE distribuyen sus ayudas. Esto lleva a ocultar, de algún modo, cómo se distribuyen geográficamente y por nivel de renta las contribuciones a la UE" algo que, como se ha apuntado, "asciende al 43\% de la ayuda española para el período 2013-2017. Así, si se asignara geográficamente ese $43 \%$ de la ayuda española que se canaliza vía instituciones de la UE, nos encontraríamos con una foto distinta" (Olivié y Pérez, 2019).

Considerando, en sintonía con Olivié y Pérez (2019), que "la ayuda distribuida por las instituciones comunitarias se reparte entre un gran número de países y poniendo el acento en la vecindad Sur y Este, así como en la región subsahariana, los datos de la ayuda española cambian sensiblemente". Así, "la ayuda dirigida a América Latina y el Caribe se reduce al 23\%, situándose como la segunda región receptora tras África, que se colocaría en el primer puesto, con un $30 \%$ de la cooperación española. Seguirían Europa (15\%) y Asia (14\%), considerando, además, que la ayuda bilateral que no puede especificarse geográficamente desciende al 18\%, desde el 39\% que representa en la distribución inicial" (Gráfico 2).

Gráfico 2. Reparto geográfico de la ayuda española, incluyendo la canalizada vía instituciones de la UE (AOD neta total en millones de dólares corrientes, acumulado 2013-2017, repartido en \%)

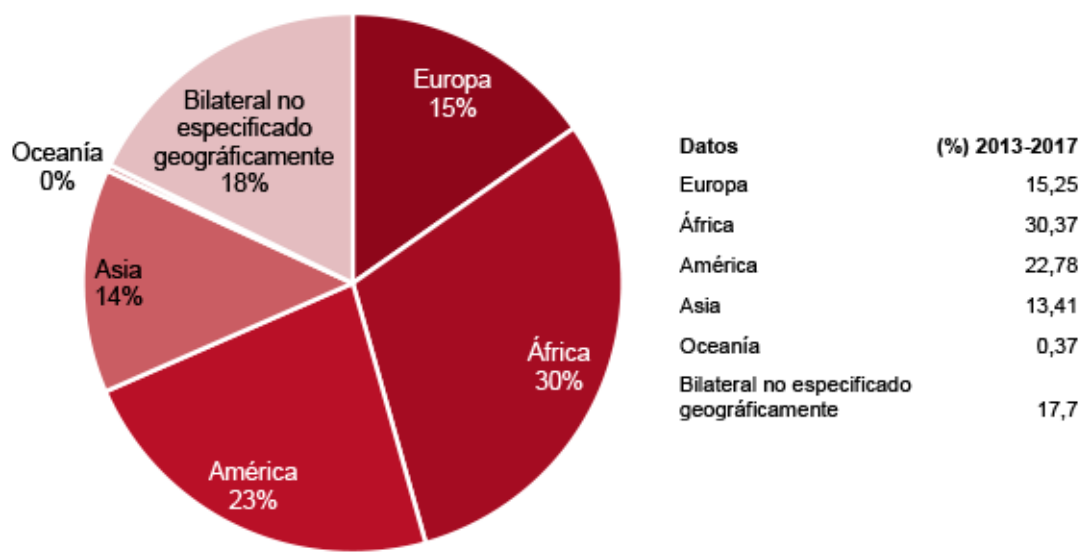

Fuente: Olivié y Pérez, 2019, basados en OCDE, OECD.Stat. 
Por todo ello, se podría decir, de acuerdo con Olivié y Pérez (2019) que la ayuda española a la cooperación "es menos latinoamericana, más africana y mucho más europea de lo que se suele pensar si se tiene en cuenta el desglose geográfico de sus contribuciones a la UE computadas como AOD”. En estas circunstancias, tal como señalan Malamud et al., "se debilita la idea de que, en el ámbito del desarrollo, España funciona como un puente entre Europa y América Latina" (Malamud et al., 2020: 63-64).

Cabe apuntar finalmente que, bajo nuestro punto de vista, este giro en la política española de cooperación está unido al desarrollo del fenómeno de las "multilatinas", con el que "Latinoamérica se ayuda a sí misma" (El País, 16 de noviembre de 2012).

\subsection{Flujos económicos de inversión directa}

Los flujos financieros, "en particular las corrientes de Inversión Extranjera Directa (IED), han constituido el ámbito más dinámico de las relaciones económicas entre España y América Latina" (González, 2020: 1152).

Los datos sobre la IED española en América Latina evidencian una tendencia creciente, habiendo atravesado la misma tres etapas durante el periodo analizado. Así, tal como apuntan Arahuetes y García, "a partir de 1993, y con mayor intensidad de 1996, se verificó una fase cíclica de intensa expansión que alcanzó su punto álgido en 2000. En 2001 las IED entraron en una nueva fase, en la que primero se registró una desaceleración hasta 2003 y, de forma inmediata, una nueva fase de expansión hasta 2006" (2007: 4). Tras la crisis financiera internacional de 2008, "se produjo una intensa desaceleración de las inversiones directas", que marcaría la etapa poscrisis (Arahuetes y Gómez, 2016: 74) (Gráfico 3). 
Gráfico 3.

\section{IED española total bruta y neta e IED bruta y neta española en América Latina, 1993-2015 (en millones de euros)}

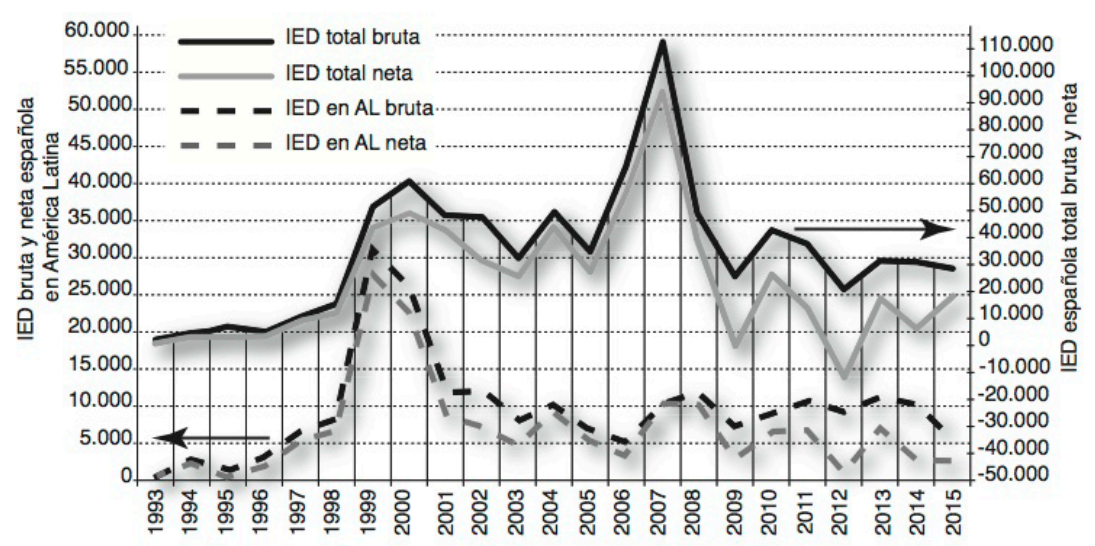

Fuente: Elaboración propia según datos de Datainvex.

Fuente: Arahuetes y Gómez, 2016: 72

En efecto, el gran salto inversor se produjo durante la década de 1990. Durante esa década, y especialmente "en la segunda mitad de los noventa, un amplio grupo de empresas, junto a las principales instituciones financieras españolas, desplegaron su expansión internacional en América Latina. España se situó entre las ocho principales economías del mundo por la cuantía de su IED, y los flujos orientados hacia las economías latinoamericanas situaron a España como el segundo país inversor directo en la región apenas detrás de EEUU" (Arahuetes, 2007: 2; Chislett, 2003: 12). Tal como señala la CEPAL, "a partir de 1994, año en que América Latina comenzó a ser el destino preferido por las empresas españolas" (2000: 140), el dinamismo del proceso se hizo evidente. Ciertamente, a partir de ese año "América Latina pasó a ser el principal destino en las estrategias de internacionalización de las más importantes empresas españolas prestadoras de servicios" [...]. Este proceso fue particularmente interesante porque en pocos años España consiguió posiciones de liderazgo en algunos de los principales mercados latinoamericanos: telecomunicaciones, energía y actividades financieras. Además, fue un proceso conducido por un grupo de no más de 10 grandes empresas, curiosamente la mayoría de ellas privatizadas hacía poco tiempo" (CEPAL, 2000: 140; Arahuetes y García, 2007: 12; Serrano, 2013: 178). Empresas tales como Telefónica de España, RepsolYPF, Endesa España y los bancos Santander Central Hispano (BSCH) y Bilbao Vizcaya Argentaria (BBVA) fueron algunas de las principales compañías 
inversoras en la región (CEPAL, 2001: 112; Chislett, 2003: 22-23; Casilda, 2005: 19-20; Arahuetes y García, 2007: 9-10).

El análisis desde la perspectiva institucional permite afirmar que las estrategias de implantación en América Latina por parte de compañías españolas estuvieron condicionadas por el diseño y construcción del marco institucional en los distintos países de la región. En concreto, el cambio en el modelo de desarrollo que supuso el fin de la Industrialización por Sustitución de Importaciones (ISI) y la implantación de un nuevo patrón de crecimiento basado en los postulados del Consenso de Washington (1989), creó un escenario sumamente favorable para que compañías privadas y extranjeras operaran en sectores vinculados al financiero y las public utilities, abriendo anuevas oportunidades de negocio, en buena parte a raíz de los abundantes procesos de privatizaciones que se llevaron a cabo en el conjunto de la región y en la liberalización de sectores regulados. Esta modificación institucional provocó un cambio en la estructura sectorial y geográfica de la inversión extranjera llegada a la América Latina; ganaron relevancia los flujos relacionados precisamente con el sector financiero y las public utilities, y la inversión española, siguiendo ese nuevo patrón, se situó en términos agregados en la segunda posición tras la inversión estadounidense, como se ha dicho (Serrano, 2013: 175-176). Fueron las privatizaciones de nuevas actividades las que atrajeron la mayor parte de las nuevas inversiones directas. Se inició, así, el despliegue de las inversiones en los sectores de telecomunicaciones-Telefónica-, energía eléctrica-Endesa, Iberdrola y Fenosa-, extracción de petróleo y comercialización de derivados -Repsol-, sobre todo con la adquisición en 1999 de YPF en Argentina; y, en segundo término, las inversiones en gas -Gas Natural-y gestión de agua y saneamiento -Aguas de Barcelona-, inmobiliarias y construcción (grandes constructoras) y hostelería -Meliá- (Arahuetes y García, 2007: 11). Así pues, los cambios institucionales registrados en América Latina supusieron un factor de atracción de un nuevo tipo de IED hacia la región latinoamericana, una inversión extranjera claramente atraída por las nuevas oportunidades derivadas de los distintos procesos de liberalización y privatización. Pero, debe matizarse este proceso y tomar en consideración el argumento esgrimido por la CEPAL de que "las firmas españolas, ante crecientes niveles de competencia en su mercado nacional y regional, aprovecharon la cercanía cultural con América Latina para iniciar un ambicioso proceso de internacionalización, basado sobre todo en la compra de activos existentes" (CEPAL, 2001: 111).

Tal como evidencian los datos, en el periodo 1992-2000, alrededor del $50 \%$ de las IED de los países de la UE hacia América Latina vinieron de España, convirtiéndose España en el mayor inversor extranjero en América Latina (CEPAL, 2002: 111). A finales de 2000 las empresas españolas habían invertido en Latinoamérica casi 72.000 millones de dólares (Tabla IV). 
Tabla IV. América Latina: principales orígenes y destinos de la IED de países de la Unión Europea, importes acumulados, 1992-2000

(En millones de dólares)

\begin{tabular}{lrrrrrrrrr}
\hline & $\begin{array}{c}\text { Argen- } \\
\text { tina }\end{array}$ & Brasil & $\begin{array}{c}\text { Mer- } \\
\text { cosur }\end{array}$ & $\begin{array}{c}\text { Co- } \\
\text { lombia }\end{array}$ & $\begin{array}{c}\text { Ven- } \\
\text { ezuela }\end{array}$ & $\begin{array}{c}\text { Comunidad } \\
\text { Andina }\end{array}$ & Chile & México & $\begin{array}{c}\text { América } \\
\text { Latina }\end{array}$ \\
\hline UE-15 & 33.746 & 63.390 & 97.810 & 7.038 & 6.508 & 20.047 & 10.686 & 11.943 & 143.821 \\
España & 24.097 & 23.484 & 47.679 & 2.714 & 1.472 & 8.324 & 8.180 & 6.009 & 71.630 \\
Portugal & 33 & 8.810 & 8.846 & 0 & 2 & 4 & 5 & 31 & 9.040 \\
R. Unido & 2.068 & 5.523 & 7.683 & 3.720 & 1.705 & 5.988 & 268 & 2.419 & 17.363 \\
Italia & 1.221 & 1.983 & 3.219 & 31 & 90 & 156 & 44 & 123 & 3.510 \\
Otros UE & 6.327 & 23.590 & 30.402 & 573 & 3.239 & 5.576 & 2.189 & 2.261 & 42.277 \\
& & & & & & & & & \\
\hline
\end{tabular}

Fuente: CEPAL, Unidad de Inversiones y Estrategias Empresariales sobre información de EUROSTAT. Visto en CEPAL, 2002: 112.

Por otro lado, en cuanto a los destinos de la IED, como señala la CEPAL, "durante la década de 1990, los dos focos centrales de las empresas españolas en América Latina fueron el Mercado Común del Sur (Mercosur) y Chile, en el Cono Sur. Durante una primera etapa se registraron importantes inversiones en Argentina y Chile, tanto con el objeto de acceder a estos mercados como de proyectarse con miras a una futura expansión al resto del Mercosur, principalmente hacia Brasil. A finales de 1997 y más plenamente en el curso de 1998, las empresas y bancos españoles comenzaron a incrementar su presencia en Brasil, el mayor mercado de la región. También la Comunidad Andina, principalmente Perú, Colombia y Venezuela, fue un foco relevante" (CEPAL, 2000: 142-143). Según los datos de la tabla, en el período 1992-2000, Argentina fue el principal destino de las inversiones españolas en América Latina. Explica la CEPAL cómo fue precisamente en este país "donde la presencia de las empresas españolas se mostró más amplia y diversificada, con una fuerte expansión en las áreas de transporte y comunicaciones, intermediación financiera, bancos y seguros, extracción de petróleo y procesamiento de combustibles, seguidas de las de energía y agua. En Chile, las inversiones se concentraron en las telecomunicaciones, la banca y la energía eléctrica [...]. En Venezuela, por su parte, las actividades más importantes fueron las bancarias. Un caso interesante, quizás no por el volumen, sino por las características de la inversión española, fue el de México. Esa economía fue el destino de las inversiones de algunas empresas manufactureras españolas, en particular en los sectores de alimentos y bebidas, industria gráfica, transformación de metales y partes de vehículo. En las inversiones españolas directas en México, la participación de las manufactureras fue superior a la media registrada en otros países de la región (y del mundo), impulsada principalmente por el Tratado de Libre Comercio de América del Norte (TLCAN)" (CEPAL, 2000: 143). 
En síntesis, en la primera etapa, durante la década de 1990, podría decirse que la IED de España en América Latina registró un crecimiento sobresaliente. No obstante, el mismo quedó limitado a un número reducido de empresas y sectores de actividad, tal como se ha comentado.

Esta etapa expansiva de las inversiones españolas en la región latinoamericana darían paso, a partir de 2001, a una nueva fase en la que, después de una retracción de la IED hasta 2003, se produjo una nueva expansión hasta 2007 (véase el Gráfico 3), situándose "los flujos de inversión en niveles muy superiores a los que habían sido característicos de los años noventa antes de los picos de 1999 y 2000" (Arahuetes y García, 2007: 4). En esta nueva etapa se produjo también un "cambio significativo en la orientación geográfica de los flujos de inversión. En la etapa 1993-2000, las inversiones españolas netas se orientaron en mayor porcentaje (61\%) hacia América Latina. Sin embargo, en la fase 2001-2006 las inversiones netas alteraron de forma notable la orientación geográfica de sus flujos, situándose los países de la UE-15/67\%) como el principal destino, seguido de América Latina (15,9\%)" (Arahuetes y García, 2007: 7) (Tabla V).

Tabla V. España: comparación de la orientación de los flujos de IED, 1993-2000， 2001-2006 y 2008-2015

(En porcentaje sobre el total)

\begin{tabular}{lrrr}
\cline { 2 - 4 } & $1993-2000$ & $2001-2006$ & $2008-2015$ \\
\hline América Latina & $61,0 \%$ & $15,9 \%$ & $28,7 \%$ \\
UE-15 & $22,5 \%$ & $67,0 \%$ & $39,6 \%$ \\
EE.UU. y Canadá & $9,0 \%$ & $6,4 \%$ & $15,6 \%$ \\
& & & \\
Otros países europeos & $2,9 \%$ & $2,1 \%$ & - \\
Países de la UE-12 & $1,2 \%$ & $5,0 \%$ & - \\
\hline
\end{tabular}

Fuente: Elaboración propia con base en los datos aportados por Arahuetes y García, 2007:7 y Arahuetes y Gómez, 2016:75.

Cabe apuntar, no obstante, junto a Arahuetes y García que, "a pesar del cambio de orientación geográfica de las inversiones españolas, hacia los países de la UE-15, las inversiones dirigidas hacia América Latina fueron superiores a las realizadas por los principales países europeos y recorrieron una trayectoria muy parecida a la seguida por las de EEUU, que fueron las más importantes" (2007: 8). Por ello, en esta etapa, Latinoamérica se mantuvo como una región atractiva para la IED española" (Arahuetes y Gómez, 2016: 73) y "se situó como el segundo país inversor en la región latinoamericana por detrás de EE.UU.” (Arahuetes y García, 2007: 22). Un aspecto novedoso en esta etapa 
fue que "las inversiones en actividades manufactureras se situaron en primer lugar con una participación del $40 \%$, y, junto a las realizadas en los sectores del periodo anterior -telecomunicaciones y actividades financieras-, destacaron las dirigidas a construcción, energía eléctrica, gas y actividades comerciales" (Arahuetes y Gómez, 2016: 73). En cuanto a los principales países receptores durante esta fase, "el $86 \%$ de los flujos de inversiones directas españolas netas se dirigieron a cuatro países: México (38\%), Brasil (23\%), Argentina (13\%) y Chile (12\%). Un segundo grupo de países recibió el $12 \%$ de la IED española: Uruguay (3\%), Perú (2,5\%), Republica Dominicana (2\%), Venezuela (2\%), Ecuador $(1,5 \%)$ y Colombia (1\%). Y, en tercer lugar, otros pequeños países recibieron el 2\% restante: Panamá, Costa Rica, Guatemala y El Salvador" (Arahuetes y Gómez, 2016: 74).

En resumen, la segunda etapa vendría caracterizada, pues, por un incremento de los flujos medios de IED española respecto al período anterior, un cambio en la orientación geográfica de las inversiones españolas, una ampliación de los sectores de origen y destino de las inversiones, y el mantenimiento del poder de atracción de América Latina para los inversores españoles.

La tercera etapa comenzaría después de la crisis financiera global de 2008, y sus efectos sobre la Eurozona en forma de crisis de la deuda soberana de 2010. En esta fase mientras que la mayoría de economías de América Latina y el Caribe crecieron a elevados ritmos muchos de los países de Europa se vieron inmersos en una recesión. Durante este período poscrisis, como explican Arahuetes y Gómez, se produjo "una intensa desaceleración de las inversiones directas internacionales, que fue más acentuada en el caso de las IED española por la naturaleza y el alcance de la crisis en España. Hasta 2008, España se situaba en la sexta posición mundial de los países que realizaban IED y en una posición similar como receptor de flujos internacionales" (2016: 74). Desde la crisis de 2008 y hasta el año 2015, "los países de la UE se situaron como nueva prioridad en la estrategia de internacionalización de las empresas españolas y, debido a ello, registraron un nuevo boom de estas inversiones de la misma forma que sucedió en el ciclo de los años noventa en América Latina" (Arahuetes y Gómez, 2016: 80). Así, el destino más importante de la IED española fueron los principales países de la UE-15, que atrajeron el 39,6\% de los flujos, seguidos de América Latina (véase Tabla V). En esta fase, la IED española cambió su perfil respecto al periodo anterior; "la industria manufactura se ha situado en segunda posición después de las telecomunicaciones, y la construcción ha superado las inversiones en actividades financieras" (Arahuetes y Gómez, 2016: 76). Por países de destino durante esta etapa, Brasil fue el principal destino de la IED española hacia Latinoamérica en esta fase, y su sector de destino más importante fue el de actividades financieras, seguido de la industria manufacturera. México fue el segundo país de destino, siendo el principal sector de destino las 
actividades financieras. Perú se situó como tercer país de destino, mostrando la orientación sectorial una elevada concentración en telecomunicaciones. Chile fue el cuarto país de destino y también el principal sector destinatario de la IED fue el de telecomunicaciones. Argentina se situó como quinto destino, y la IED se dirigió a la industria manufacturera (Arahuetes y Gómez, 2016: 76-79).

Todo ello hace que resulte incuestionable, bajo nuestro punto de vista, la idea de que después de la crisis de 2008 se alteró el papel de España en América Latina. Y ello no puede disociarse del cambio en la correlación de fuerzas entre España y los países más desarrollados de América Latina, puesto en evidencia por la dinámica y el volumen de su PIB (Tabla VI).

Tabla VI. España, Brasil, México, Argentina: comparación del PIB (miles de millones de dólares, a precios corrientes)

\begin{tabular}{lrrrrrrrrrrrrrrrrr}
\hline País & 2005 & 2006 & 2007 & 2008 & 2009 & 2010 & 2011 & 2012 & 2013 & 2014 & 2015 & 2016 & 2017 & 2018 & 2019 \\
& & & & & & & & & & & & & \\
\hline España & 1.153 & 1.259 & 1.472 & 1.625 & 1.485 & 1.420 & 1.478 & 1.324 & 1.354 & 1.369 & 1.195 & 1.232 & 1.312 & 1.422 & 1.393 \\
Brasil & 891 & 1.107 & 1.397 & 1.695 & 1.667 & 2.208 & 2.616 & 2.465 & 2.472 & 2.455 & 1.802 & 1.795 & 2.062 & 1.885 & 1.839 \\
México & 877 & 975 & 1.052 & 1.109 & 900 & 1.057 & 1.180 & 1.201 & 1.274 & 1.315 & 1.171 & 1.078 & 1.158 & 1.222 & 1.268 \\
Argentina & 198 & 232 & 287 & 361 & 337 & 423 & 530 & 45 & 552 & 526 & 594 & 557 & 643 & 517 & 445 \\
\hline
\end{tabular}

Fuente: Banco Mundial.

Resulta muy significativo que en el periodo de los años 2008-2012, el PIB de España a precios corrientes se redujo en más del 18\%, mientras que el mismo indicador de México creció en más del 8\%, el de Brasil lo hizo al 45\% y el de Argentina a casi el 51\%. En 2008 el PIB de Brasil y España estaban prácticamente igualados y en 2012 el PIB brasileño casi duplicaba al español. Todo ello ha reforzado la opinión de algunos analistas en el sentido de que América Latina ha podido reforzar "cardinalmente sus posiciones económicofinancieras $\mathrm{y}$, como consecuencia, sus posiciones en las negociaciones internacionales" (Yákovlev, 2013: 114) y "ya no requiere que España o la UE alcancen sus objetivos globales, y tampoco busca inspiración política o económica en ninguno de los dos" (Torreblanca, 2010).

\section{Conclusiones: propuestas de acción a futuro}

De lo expuesto en los apartados anteriores, se pueden extraer algunas reflexiones generales y proponer ciertas acciones de futuro.

a) En relación con el planteamiento de la "historia compartida" entre España y el conjunto de los países que componen América Latina. Esta visión 
clásica idealizada es correcta, pero esconde algunos problemas. Primero, hay que recordar que el país mayor de América Latina tiene una conexión con el mundo cultural luso y no con el hispano. El PIB de Brasil fue en 2019 el más alto de la región (32\%); y su población alcanzó 215 millones de habitantes en la misma fecha (35\% de la población total de América Latina). Segundo, América Latina contiene una diversidad de culturas autóctonas que siguen manteniendo en 2021 parte de sus tradiciones y costumbres. Tercero, desde la independencia a comienzos del siglo XIX las sociedades de América Latina fueron recibiendo influencias culturales de Francia, Gran Bretaña, Estados Unidos, Alemania, Italia y recientemente de los países asiáticos (China en especial) con diversas intensidades según las épocas y los países. Las familias más acomodadas de América Latina prefieren enviar hoy a sus hijos a estudiar a Estados Unidos, Francia o Gran Bretaña que a España. Los grandes negocios se hacen en inglés y la ciencia se escribe en inglés. Cuarto, en las últimas décadas el protestantismo y las religiones evangélicas se han extendido a ritmos acelerados en América Latina. Quinto, las independencias construyeron imaginarios identitarios nacionales excluyentes que fomentaron la rivalidad entre los países entre sí, lo cual se ha traducido en la dificultad de alcanzar consensos supranacionales. Sexto, buena parte de las economías de América Latina son competitivas entre sí, en vez de complementarias, y siguen mostrando un perfil dependiente de los mercados exteriores (capitales y mercancías). En suma, si bien en España se sigue hablando de una iberoamericanidad cohesionada por su herencia cultural hispana, ese sentimiento es rechazado por buena parte de la población latinoamericana por recordar precisamente la herencia colonial de la que se quieren desprender. Prueba de la dificultad de construir una unidad económica latinoamericana es que al día de la fecha no se ha logrado alcanzar una integración comercial basada en un régimen arancelario común, no se ha avanzado en la construcción de una moneda común, no se ha construido un régimen fiscal compartido, y las distintas experiencias de los proyectos de integración económica han mostrado problemas. La idea de construir un proyecto político compartido en la región suena de momento como una utopía no solo irrealizable, sino no deseable debido a los vivos discursos nacionalistas excluyentes. El débil funcionamiento del Parlatino es una prueba de ello. América Latina está compuesta por países que compiten entre sí. Utilizando una frase manida, se puede decir que no existe un teléfono al que llamar cuando se quiere contactar con la región (Pérez Herrero, 2010).

b) Respecto a los efectos positivos de las inversiones realizadas por las empresas y los bancos españoles en América Latina junto con la cooperación ofrecida por los gobiernos españoles en el desarrollo económico y social de los países de América Latina. Esta afirmación es cierta. No se puede negar que las 
inversiones realizadas por las empresas, junto con las ayudas en AOD y créditos FAD dados por los gobiernos, se tradujeron en un aumento de la producción y de las exportaciones. Pero hay que recordar además que se deben añadir algunos datos a fin de distinguir los beneficios brutos de los netos. Primero, algunas de las empresas que desembarcaron en América Latina a partir de 1990 lo hicieron buscando salarios bajos y recibieron tratos preferenciales de los gobiernos de los países respectivos, por lo que no sólo no ayudaron a mejorar las condiciones sociales de muchos de los trabajadores que contrataron, sino que además preservaron en unos casos y fortalecieron en otros la corrupción. No contamos al día de la fecha con un índice de correlación fiable que demuestre que en los países que recibieron inversiones de las empresas españolas se redujera el paro y la informalidad y mejorara el nivel de vida de la población. Segundo, algunas de las empresas españolas reinvirtieron una reducida cantidad de sus ganancias en los países donde se habían generado, quebrándose el ciclo del desarrollo productivo. Tercero, algunas empresas no fueron demasiado respetuosas con la preservación del medio ambiente. Cuarto, en algunas ocasiones las inversiones realizadas se hicieron en un escenario marcado por una coyuntura beneficiosa (nacional o internacional), por lo que cuando esta se modificó las empresas desaparecieron dejando a veces tras de sí rompimientos en las cadenas de producción, más paro y una extensión de la informalidad. Quinto, algunas empresas no pagaron todos los impuestos que deberían haber hecho en los países donde habían obtenido sus ganancias, reduciendo los ingresos de los erarios públicos. Sexto, las inyecciones españolas de AOD y los créditos FAD sirvieron en algunos casos para apoyar a las empresas españolas que pretendían establecerse en América Latina, en vez de ayudar a que los pequeños y medianos empresarios latinoamericanos aumentaran su competitividad. Séptimo, muchas de estas apreciaciones se pueden trasladar también a las empresas multilatinas que operan en España en la actualidad. En suma, por lo general, han primado los beneficios económicos de corto plazo sobre los beneficios sociales de largo plazo, lo cual es lógico desde la perspectiva empresarial. El problema surge cuando se ha tratado de defender las acciones de estas empresas poniendo en valor los beneficios sociales que dicen haber generado.

c) Sobre la política de apoyo mostrado por los gobiernos españoles a América Latina. Sin duda es una afirmación cierta. Los datos de la AOD y de la cooperación así lo atestiguan. No obstante, es necesario hacer algunas matizaciones. Primero, para lograr el ingreso de España en la entonces llamada Comunidad Económica Europea el gobierno de Felipe González argumentó hábilmente que España servía de puente o gran centralita de comunicaciones para ayudar a Europa a ampliar sus mercados y ampliar sus inversiones en América Latina. Este argumento no gustó mucho en América Latina pues se daba a entender 
que desde allí no se podían conectar directamente con los países europeos y que por tanto debían seguir estando tutelados por su antigua metrópoli. Segundo. Durante los primeros gobiernos de Felipe González se impulsaron políticas activas para lograr la paz en Centroamérica y expandir las formas democráticas en aquellos países en los que aún perduraban los regímenes militares, pero una vez que llegó al poder José María Aznar (1996-2004) América Latina pasó a convertirse, con el apoyo de la diplomacia, en la pista de aterrizaje de las empresas españolas. Eran los momentos en los que los planteamientos neoliberales gozaban de más prestigio. Durante los gobiernos de José Luis Rodríguez Zapatero (2004-2011) se ampliaron los fondos de cohesión y las empresas redujeron sus inversiones como resultado de la crisis de 2008. Durante los gobiernos de Mariano Rajoy (2011-2018) se redujo la cooperación al mínimo por la caída de los ingresos y los recortes presupuestarios. Finalmente, durante los gobiernos de Pedro Sánchez la cooperación con América Latina se redujo no solo por los continuos recortes presupuestarios, sino además porque muchos de los países de América Latina habían dejado de ser receptores de ayudas por haber elevado su nivel de renta. Todo ello muestra que, a pesar de las continuas declaraciones de la importancia de América Latina para España, en los últimos años no ha habido una política clara de largo plazo de qué hacer en la región. América Latina ha acabado siendo vista prioritariamente como un espacio económico. Tercero, resulta llamativo que no se haya hecho una cumbre de jefes de Estado para tratar de dar solución a las necesidades urgentes que tienen muchos de los países que conforman la denominada región iberoamericana (América Latina, España, Portugal). Se cita siempre la existencia de la desigualdad, la corrupción, el hambre, la violencia, el narcotráfico, el paro, la informalidad y la desafección política; la necesidad de aumentar la productividad y la competitividad; la urgencia de reducir la dependencia externa, ampliar las clases medias, mejorar los niveles educativos $\mathrm{y}$ fortalecer al funcionamiento de los partidos políticos, pero al día de la fecha no se ha diseñado un plan director con estos temas. Las miopías políticas nacionalistas siguen impidiendo alcanzar consensos de largo plazo. Las cumbres iberoamericanas y las reuniones ALC-UE-siguen siendo (cuando se celebran) foros con muchos discursos y pocos resultados. Pareciera que sus acuerdos se hubieran firmado con tinta invisible (Pérez Herrero, 2015).

d) En cuanto a la relevancia de las relaciones de España y de la Unión Europea con América Latina. Se sigue subrayando la importancia del castellano, pero no se ha hecho casi nada para aprovechar esta ventaja comparativa. Resulta sintomático comprobar que los gobiernos españoles y latinoamericanos, tanto conservadores como progresistas, a lo largo de los últimos 40 años no hayan comprendido la importancia social, política y cultural que representa el potencial de Iberoamérica. En educación no se ha construido una red de universidades 
y no se ha creado un sistema de becas bien financiado como el Erasmus. En investigación no se han hecho las inversiones necesarias para generar una red de centros de investigación punteros capaces de potenciar sinergias y maximizar beneficios. Cine, literatura, teatro, música, arte, gastronomía, turismo y un largo etcétera siguen olvidados, cuando deberían haberse vistos como los buques insignia para crear una potente "marca iberoamericana". Se sigue dependiendo de las productoras cinematográficas estadounidenses y continuamos estando colonizados por sus planteamientos simplistas llenos de violencia. Pareciera como si no hubiera habido 11 premios nobel en literatura en castellano (España 5, Chile 2, Colombia 1, Guatemala 1, México 1, Perú 1) y uno en portugués.

e) Sobre las estrategias a largo plazo. En el mundo globalizado y competitivo de 2021 se sigue sosteniendo por muchos pensadores y analistas la importancia de la región iberoamericana, sin querer reconocer que además se debería comenzar a pergeñar estrategias de largo plazo más ambiciosas. América Latina, la Unión Europea, Estados Unidos, Canadá y los países africanos de la vertiente atlántica deberían comprender la importancia de generar un espacio atlántico de acción basado en el reconocimiento de las diferencias (de cultura, género, edad, religión, lengua). No se trata impulsar una homogeneización cultural, sino de establecer estrategias de colaboración que generen economías de escala con los eslabonamientos internos que ayuden a ampliar la productividad, que fortalezcan la formación de capital social, y que favorezcan la construcción de marcos políticos que restablezcan la confianza en la democracia y posibiliten la coexistencia pacífica de las múltiples identidades existentes. Un proyecto plural de largo plazo compartido de este tipo tiene más capacidad de integración que la apuesta por potenciar un idioma o una religión. Se deben superar los proyectos basados en inversiones ancladas en la utilización de mano de obra barata o en la adquisición de materias primas a precio de saldo. Se debe construir un proyecto de desarrollo económico, social, político y cultural integral basado en el fortalecimiento de la dignidad de las personas y en el respeto al medioambiente. Se requiere potenciar la sociedad del bienestar y preservar el funcionamiento transparente de las instituciones. La creación del espacio atlántico no es una opción, es una necesidad. Los países asiáticos, que suponen el $60 \%$ de la población mundial, acaban de firmar el acuerdo comercial mayor del planeta. China tiene un proyecto de largo plazo claro y su PIB pronto será superior al de Estados Unidos. La población de África representa el 17\% de la población mundial, la de Europa el 10\%, la de América Latina el 8\%, y la de Estados Unidos y Canadá el 5\%. Si se quiere llegar a buen puerto, no parece conveniente seguir tratando de navegar en las aguas de la globalización utilizando los referentes de las fronteras territoriales y conceptuales nacionales creadas en el siglo XIX (Pérez Herrero 2020). La pandemia de la COVID 19 nos ha puesto sobre aviso. Vivimos en un mundo 
que requiere soluciones globales. ¿Por qué seguir fijando nuestro horizonte en la región iberoamericana cuando podemos hacerlo en el espacio atlántico?

\section{Referencias bibliográficas:}

Arahuetes, A., y Argüelles, J. (1996): «Las inversiones directas de España en América Latina», Revista CIDOB d'Afers Internacionals, $\mathrm{n}^{\circ}$ 31: 119-146.

Arahuetes, A. y García, A. (2007): “¿Qué ha sucedido con la Inversión Extranjera Directa (IED) de las empresas españolas en América Latina tras el boom de los años noventa y la incertidumbre de los primeros años 2000?", Documento de Trabajo No 35/2007 Real Instituto Elcano. http://biblioteca.ribei.org/1291/1/DT-35-2007-E.pdf

Arahuetes, A. y Gómez, G. (2016): "Las inversiones directas españolas en América Latina en el período 2009-16", Economía exterior: estudios de la revista Politica Exterior sobre la internacionalización de la economía española, $\mathrm{N}^{0}$ 78: 69-81.

Arriola, S., Garranzo, R. y Ruiz Jiménez, L. (coords.) (2013): La renovación de la cooperación iberoamericana. Transformaciones para una agenda post-2015, Madrid: SEGIB y AECID.

Barbé, E. (2009): “Tensiones de la política exterior española hacia América Latina: comunidad, imagen y liderazgo", en C. del Arenal (coord.), España y América Latina 200 años después de la Independencia. Valoración y perspectivas. 123-150. Madrid: Real Instituto Elcano/Marcial Pons.

Casanueva, H. (coord.) (2020): Unión Europea y América Latina. Una asociación estratégica para los desafios globales, Madrid: Marcial Pons, Colección Instituto de Estudios Latinoamericanos.

Casilda, R. (2000): La década dorada. Economía e inversiones españolas en América Latina 1990-2000. Universidad de Alcalá: Servicio de Publicaciones.

- (2005): "Internacionalización e inversiones directas españolas en América Latina 2000-2004: situación y perspectivas", Documentos CIDOB. Serie América Latina, $\mathrm{N}^{\mathrm{0}} 5$.

Chislett, W. (2003): La Inversión Española Directa en América Latina: Retos y Oportunidades, Madrid: Real Instituto Elcano de Estudios Internacionales y Estratégicos.

Comisión Económica para América Latina y el Caribe (CEPAL) (2019): La Inversión Extranjera Directa en América Latina y el Caribe 2019, Santiago: Publicación de las Naciones Unidas.

- (2018): La inversión extranjera en América Latina y el Caribe 2018, Santiago: Publicación de las Naciones Unidas.

- (2002): La inversión extranjera en América Latina y el Caribe 2001, Santiago: Publicación de las Naciones Unidas.

- (2000): La inversión extranjera en América Latina y el Caribe 1999, Santiago: Publicación de las Naciones Unidas.

Del Arenal, C. (1994): Politica exterior de España hacia Iberoamérica, Madrid: Ed. Complutense.

(2011a): Política exterior de España y relaciones con América Latina. Iberoamericanidad, Europeización y Atlantismo en la política exterior española, Madrid: Fundación Carolina en coedición con Siglo XXI de España Editores, S.A. 
- (2011b): “La triangulación España-Unión Europea-América Latina: sinergias y contradicciones", Pensamiento Iberoamericano, Volumen 8: 72101. https://eulacfoundation.org/es/system/files/Triangulacion_Espana-UEAm\%C3\%A9rica\%20Latina.pdf

Delgado, L. (2003): "La política latinoamericana de España en el siglo XX", Ayer, 49: 121-160.

Fazio Vengoa. H. (2000): “América Latina en la política exterior de España”. Historia Crítica, 20: 40-66. https://revistas.uniandes.edu.co/doi/10.7440/histcrit20.2000.02 https://revistas.uniandes.edu.co/doi/10.7440/histcrit20.2000.02

Freres, Ch. (2011): "La cooperación española en América Latina: en busca de un marco estratégico", Documentos de Trabajo Fundación Carolina, №. 46: 57-69. https:// www.academia.edu/31344773/La cooperaci $\% \mathrm{C} 3 \% \mathrm{~B} 3 \mathrm{n}$ espa $\% \mathrm{C} 3 \% \mathrm{~B} 1 \mathrm{ola}$ en Am\%C3\%A9rica_Latina_En busca_de un marco_estrat $\% \mathrm{C} 3 \%$ A9gico

García, A.; Jiménez, B. y Redondo, A. (2009): "La inmigración latinoamericana en España en el siglo XXI", Investigaciones Geográficas, Boletín del Instituto de Geografia, UNAM, Núm. 70: 55-70.

González Sarro, I. (2020): “Veinte años de relaciones estratégicas de la Unión Europea con América Latina y el Caribe (1999-2019): análisis de la evolución de sus «tres pilares» fundamentales", Foro Internacional, vol. LX-3, Núm. 241: 1121-1167.

Haider, W. y Clemente, I. (Coord.) (2020): Revisiting bi-regional relations: The EU-Latin American dialogue and diversification of interregional cooperation, Hamburg: EULAC Foundation.

Jorge, D. (Coord.) (2018): Tan lejos, tan cerca. Miradas contemporáneas entre España y América Latina, Valencia: Tirant Humanidades.

Malamud, C.; Olivié, I. y Escribano, G. (2020): Las relaciones España-América Latina en tiempos del COVID-19, Informe 29, Madrid: Real Instituto Elcano.

Olivié, I. y Pérez, A. (2019): “¿Dónde está la ayuda española?”, ARI 49/2019, Real Instituto Elcano Royal Institute.

Pérez Herrero, P. (2003): "Las relaciones de España con América Latina durante los siglos XIX y XX. Discursos gubernamentales y realidades", en Pereira, J. C. (coord.), La política exterior de España (1800-2003): historia, condicionantes y escenarios, Madrid: Ariel, 319-340.

- (2010): "Las relaciones de España con América Latina (1810-2010): discursos, políticas y realidades", en Juan Carlos Pereira (Coord.), La política exterior de España (1800-2010), Barcelona: Ariel, pp. 417-440.

- (2015):“La relación especial de España y América Latina. La búsqueda del entendimiento", en José María Beneyto y Juan Carlos Pereira (Dirs.), Historia de la política exterior española en los siglos XX y XXI, 2 Vols., Madrid: CEU Ediciones, vol. II, págs. 209-239.

- (2020): "Imaginando el futuro de la Asociación de América Latina y el Caribe con la Unión Europea”, en Casanueva. H. (Coord.), Unión Europea y América Latina. Una asociación estratégica para los desafios globales, Madrid: Marcial Pons, 109-132.

Rodríguez, A. (2018): “América Latina y España: ¿hacia una relación igualitaria?”, Relaciones Internacionales, 38: 215-223.

Serrano, E. (2013): "La inversión española directa en América Latina ¿Un proceso impulsado a partir de la empresa pública? “, Revista de Historia Industrial, N. ${ }^{\text {53: }}$ 175-211. https://core.ac.uk/download/pdf/95615863.pdf 
Torreblanca, I. (2010): "Foreign policy needs a rethink above and beyond Europe", The Financial Times, 9 de junio. https://www.ft.com/content/0d38ed5c-71d2-11df-8eec$\underline{00144 \mathrm{feabdc} 0}$

Vodusek, Z. (ed.) (2002): Inversión extranjera directa en América Latina El papel de los inversores europeos, Washington, DC.: Banco Interamericano de Desarrollo.

Yákovlev, Petr (2013): "España y Latinoamérica: cambio cualitativo de relaciones", Iberoamérica, 2: 91-121. 